\title{
Randomized controlled trial about pain medication flupirtine ignores recent pharmacovigilance warnings
}

This article was published in the following Dove Press journal: Journal of Pain Research

\section{Livia Puljak ${ }^{1,2}$}

'Laboratory for Pain Research, University of Split School of Medicine, Split, Croatia; ${ }^{2}$ Department for Development, Research and Health Technology Assessment, Agency for Quality and Accreditation in Health Care and Social Welfare, Zagreb, Croatia
Correspondence: Livia Puljak Laboratory for Pain Research, University of Split School of Medicine, Soltanska 2, 21000 Split, Croatia

Tel +385 2l 557807

Fax +385 2I 5578 II

Email livia@mefst.hr

\section{Dear editor}

On October 16, 2017 in the Journal of Pain Research, a randomized controlled trial (RCT) comparing efficacy and safety of flupirtine versus piroxicam in postoperative pain in patients undergoing lower limb surgery was published. ${ }^{1}$ However, this paper fails to report important information.

First, the paper describes a study in which flupirtine, a pain medication, was used. Because pharmacovigilance signals potentially severe liver toxicity, in 2013 the European Medicines Agency (EMA) recommended restrictions in the use of flupirtine-containing medications. ${ }^{2}$ According to those restrictions, flupirtine-containing medications need to be used only for short-term pain when other analgesics are contraindicated, that is, for not more than 14 days; the drug should not be given to people with preexisting liver disease, alcohol abuse, or other hepatotoxic drugs. Liver function should also be monitored after each week of therapy and the treatment should be discontinued if there are any signs of liver problems. ${ }^{2}$ The recommendation about restricting therapy to 14 days was based on the EMA's observation that "no cases of liver failure or liver transplantation were reported for patients that were taking flupirtine-containing medicines for 2 weeks or less." ${ }^{2}$

However, in 2014, Douros et al $^{3}$ analyzed cases of flupirtine-induced liver injury (FILI) in Germany as well as severe cases of hepatotoxicity from the database of German drug regulator, and concluded that even though the risk of liver toxicity is higher after 14 days, that an even earlier onset of severe FILI cannot be ruled out. Last year, an association between haplotype DRB1*16:01-DQB1*05:02 and FILI was reported. ${ }^{4}$

Considering all these information about potential severe liver toxicity induced by flupirtine, it is surprising that a new RCT being published does not even mention flupirtine's potential to induce hepatotoxicity, and that measurements of liver enzymes were also not reported. The only information in the "Introduction" section regarding flupirtine safety is "It is devoid of adverse effects like gastritis, renal compensation, and respiratory depression and therefore found to be safe in most patients."

This trial was reportedly conducted from January 2015 to July 2016, when information related to liver toxicity and flupirtine safety were already available. Regulatory warnings about drugs should be utilized to introduce appropriate safety monitoring in clinical trials and to ensure patient safety. 
Second, the paper describes an RCT conducted on humans and details about the trial registration were not mentioned. Since 2005, International Committee of Medical Journal Editors requires mandatory prospective registration of clinical trials. If there are trials registered, which plan to use medicines that are subject of regulatory warnings, principal investigators can be contacted and could be warned about recent pharmacovigilance signals related to patient safety.

\section{Disclosure}

The author reports no conflicts of interest in this communication.

\section{References}

1. Chinnaiyan S, Sarala N, Arun HS. A comparative study of efficacy and safety of flupirtine versus piroxicam in postoperative pain in patients undergoing lower limb surgery. J Pain Res. 2017;10:2471-2477.

2. European Medicines Agency. PRAC Recommends Restricting the Use of Flupirtinecontaining Medicines. London, UK: European Medicines Agency; 2013. Available from: http://www.ema.europa.eu/docs/en_GB/ document_library/Referrals_document/Flupirtine-containing_medicines/Recommendation_provided_by_Pharmacovigilance_Risk_Assessment_Committee/WC500144453.pdf.

3. Douros A, Bronder E, Andersohn F, et al. Flupirtine-induced liver injury-seven cases from the Berlin Case-control Surveillance Study and review of the German spontaneous adverse drug reaction reporting database. Eur J Clin Pharmacol. 2014;70(4):453-459.

4. Nicoletti P, Werk AN, Sawle A, et al. HLA-DRB1*16: 01-DQB1*05: 02 is a novel genetic risk factor for flupirtine-induced liver injury. Pharmacogenet Genomics. 2016;26(5):218-224. 


\section{Authors' reply}

Sowmya Chinnaiyan'

Narayana Sarala'

Heddur Shanthappa Arun²

'Department of Pharmacology, ${ }^{2}$ Department of Orthopedics, Sri Devaraj Urs Medical College, Sri Devaraj Urs Academy of Higher Education and Research, Kolar, Karnataka, India

Correspondence: Narayana Sarala

Department of Pharmacology, Sri Devaraj Urs Medical College, Sri

Devaraj Urs Academy of Higher Education and Research, Tamaka, Kolar, Karnataka, 563103, India

Tel +91 9845750165

Email n_sarala@rediffmail.com

\section{Dear editor}

We thank Livia Puljak for the valuable insights on the article titled "A comparative study of efficacy and safety of flupirtine versus piroxicam in postoperative pain in patients undergoing lower limb surgery" published in the Journal of Pain Research. The concerns highlighted in the Letter to the Editor have been answered.

As per the 2013 European Medicines Agency recommendations stated in the letter, flupirtine-containing medications need to be used only for short-term pain when other analgesics are contraindicated, for not more than 14 days: We have used flupirtine only for a short duration of 5 days as mentioned in the paper on page 2472 (lines 9 and 10). ${ }^{1}$ We have adhered to the guidelines for the use of flupirtine as per the drug regulatory board in our country. ${ }^{2}$

The recommendation also states that flupirtine should not be given to people with preexisting liver disease, alcohol abuse, or other hepatotoxic drugs: This has been mentioned as part of the exclusion criteria stated on page 2472 (lines 33 and 38). ${ }^{1}$ The literature search done before the commencement of our study revealed that short-term therapy usually did not elevate the liver enzymes, and so we highlighted only the advantages and safety features of flupirtine over piroxicam in the "Introduction" section. We missed directly pointing out the hepatotoxic potential of flupirtine on long-term administration in the introduction; although it was unintentional, we regret the error. We have, however, clearly defined in the exclusion criteria that patients with preexisting liver disease have been excluded.

Although hepatotoxicity has been reported with the longterm use of flupirtine, we also came across studies in literature that did not show hepatotoxicity even on long-term administration. In studies on tinnitus patients (24 patients treated with $2 \times 100 \mathrm{mg} / \mathrm{d}$ for 3 weeks) ${ }^{3}$ or Creutzfeldt-Jakob disease patients ( 13 patients treated with $3-4 \times 100 \mathrm{mg} / \mathrm{d}$ for up to 10 months), ${ }^{4}$ elevated liver enzymes were not reported. After repeated treatment for 8 days, medication-related adverse events were not observed, and the liver function tests were within normal range among all subjects. ${ }^{5}$

For the statement "liver function should be monitored after each week of therapy and treatment should be discontinued if any signs of liver problems occur," in our study, the duration of treatment with flupirtine (100 mg twice daily) was only for 5 days as mentioned in the paper. During this period, none of our patients showed any clinical features of liver derangement and the liver function tests done on day 6 were normal. Since the enzyme levels were within normal limits, it was not mentioned in the "Discussion" section.

As per Douros et al, ${ }^{6}$ even though the recommended duration of treatment is less than or equal to 2 weeks, earlier onset of severe flupirtine-induced liver injury cannot be ruled out.

This could be because of subject-to-subject variation to drug response, which may be associated with or can occur due to concomitant use of hepatotoxic drugs, the dose of flupirtine, the duration of treatment, alcohol abuse, and genetic basis (as in Nicoletti et al). ${ }^{7}$ We have taken precautions to exclude the patients with clinical evidence of liver injury or by liver function tests. The patients in our study did not manifest with flupirtine-induced liver damage clinically or subclinically.

The pharmacogenetics study by Nicoletti et $\mathrm{al}^{7}$ was published much later to the study conducted at our center. This information is very much appreciated, and we would try to include it in the future studies.

Registration of a study is a valuable suggestion that can certainly help the investigators to receive inputs regarding the drug safety from researchers worldwide. As mentioned in the paper, ours was a randomized, open-label, parallelgroup, comparative study, postmarketing surveillance of approved medication and not a clinical trial. Because of logistic and technical issues, we were unable to register the study on time.

\section{Disclosure}

The authors report no conflicts of interest in this communication.

\section{References}

1. Chinnaiyan S, Sarala N, Arun HS. A comparative study of efficacy and safety of flupirtine versus piroxicam in postoperative pain in patients undergoing lower limb surgery. J Pain Res. 2017;10:2471-2477.

2. LIST OF APPROVED DRUG FROM 01.01.2010 TO 31.12.2010 [Internet]. Available from: http://www.cdsco.nic.in/writereaddata/LIST-OFAPPROVED-DRUG-FROM-01-01-2010-TO-31-12-2010.pdf. Accessed December 4, 2017. 
3. Salembier L, De Ridder D, van de Heyning PH. The use of flupirtine in treatment of tinnitus. Acta Otolaryngol Suppl. 2006;556:93-95.

4. Otto M, Cepek L, Ratzka P, et al. Efficacy of flupirtine on cognitive function in patients with CJD: A double-blind study. Neurology. 2004;62:714-718.

5. Siegmund W, Modess C, Scheuch E, et al. Metabolic activation and analgesic effect of flupirtine in healthy subjects, influence of the polymorphic NAT2, UGT1A1 and GSTP1. Br J Clin Pharmacol. 2014;79:501-513.
6. Douros A, Bronder E, Andersohn F, et al. Flupirtine-induced liver injuryseven cases from the Berlin Case-control Surveillance Study and review of the German spontaneous adverse drug reaction reporting database. Eur J Clin Pharmacol. 2014;70(4):453-459.

7. Nicoletti P, Werk AN, Sawle A, et al. HLA-DRB1*16: 01-DQB1*05: 02 is a novel genetic risk factor for flupirtine-induced liver injury. Pharmacogenet Genomics. 2016;26(5):218-224.

Dove Medical Press encourages responsible, free and frank academic debate. The content of the Journal of Pain Research 'letters to the editor' section does not necessarily represent the views of Dove Medical Press, its officers, agents, employees, related entities or the Journal of Pain Research editors. While all reasonable steps have been taken to confirm the content of each letter, Dove Medical Press accepts no liability in respect of the content of any letter, nor is it responsible for the content and accuracy of any letter to the editor.

\section{Journal of Pain Research}

\section{Publish your work in this journal}

The Journal of Pain Research is an international, peer reviewed, open access, online journal that welcomes laboratory and clinical findings in the fields of pain research and the prevention and management of pain. Original research, reviews, symposium reports, hypothesis formation and commentaries are all considered for publication.
Dovepress

The manuscript management system is completely online and includes a very quick and fair peer-review system, which is all easy to use. Visit http://www.dovepress.com/testimonials.php to read real quotes from published authors. 